\title{
Effects of cholesterol content on activity of P-glycoproteins and membrane physical state, and consequences for anthelmintic resistance in the nematode Haemonchus contortus
}

\author{
Mickaël Riou ${ }^{1,2, a, *}$, Fabrice Guégnard ${ }^{2}$, Yves Le Vern ${ }^{2, b}$, Isabelle Grasseau ${ }^{3}$, Christine Koch ${ }^{2}$, Elisabeth Blesbois ${ }^{3}$, \\ and Dominique Kerboeuf ${ }^{2, c}$ \\ ${ }^{1}$ INRAE, UE-1277 Plateforme d'infectiologie expérimentale (PFIE), Centre de Recherche Val de Loire, 37380 Nouzilly, France \\ 2 INRAE, Université de Tours, UMR-1282 Infectiologie et Santé Publique (ISP), Centre de Recherche Val de Loire, 37380 Nouzilly, \\ France \\ ${ }^{3}$ INRAE, CNRS, HARAS NATIONAUX, IFCE, Université de Tours, UMR-0085 PRC Physiologie de la Reproduction et des \\ Comportements, Centre de Recherche Val de Loire, 37380 Nouzilly, France
}

Received 27 May 2019, Accepted 27 December 2019, Published online 14 January 2020

\begin{abstract}
Eukaryote plasma membranes protect cells from chemical attack. Xenobiotics, taken up through passive diffusion, accumulate in the membranes, where they are captured by transporters, among which P-glycoproteins (Pgps). In nematodes such as Haemonchus contortus, eggshells and cuticles provide additional protective barriers against xenobiotics. Little is known about the role of these structures in the transport of chemical molecules. Pgps, members of the $\mathrm{ABC}$ transporter family, are present in eggshells and cuticles. Changes in the activity of these proteins have also been correlated with alterations in lipids, such as cholesterol content, in eggshells. However, the cellular mechanisms underlying these effects remain unclear. We show here that an experimental decrease in the cholesterol content of eggshells of Haemonchus contortus, with Methyl-beta-CycloDextrin (M $\beta C D)$, results in an increase in membrane fluidity, favouring Pgp activity and leading to an increase in resistance to anthelmintics. This effect is modulated by the initial degree of anthelminthic resistance of the eggs. These results suggest that eggshell fluidity plays a major role in the modulation of Pgp activity. They confirm that Pgp activity is highly influenced by the local microenvironment, in particular sterols, as observed in some vertebrate models. Thus, eggshell barriers could play an active role in the transport of xenobiotics.
\end{abstract}

Key words: Parasite, Eggshell, M $\beta C D$, Fluidity, Cholesterol, P-glycoproteins, Resistance, Anthelmintics.

\begin{abstract}
Résumé - Effets de la teneur en cholestérol sur l'activité des glycoprotéines $P$ et sur l'état physique de la membrane, et conséquences pour la résistance aux anthelminthiques chez le nématode Haemonchus contortus. Les membranes plasmiques des eucaryotes protègent les cellules contre les attaques chimiques. Les xénobiotiques, absorbés par diffusion passive, s'accumulent dans les membranes où ils sont capturés par des transporteurs, parmi lesquels les glycoprotéines P (Pgp). Chez les nématodes, les coques des œufs et les cuticules constituent des barrières de protection supplémentaires contre les xénobiotiques. On en sait peu sur le rôle de ces structures dans le transport des molécules chimiques. Les Pgp, membres de la famille des transporteurs ABC, sont présents dans les coques et les cuticules. Des changements dans l'activité de ces protéines ont également été mis en corrélation avec des altérations des lipides, tels que la teneur en cholestérol, des coques des œufs. Cependant, les mécanismes cellulaires sous-jacents à ces effets restent flous. Nous montrons ici que la diminution expérimentale de la teneur en cholestérol des coques des œufs d'Haemonchus contortus, avec la méthyl-beta-cyclodextrine (MBCD), entraîne une augmentation de la fluidité membranaire favorisant l'activité des Pgp et une augmentation de la résistance aux anthelminthiques. Cet effet est modulé par le degré initial de résistance aux anthelminthiques des œufs. Ces résultats suggèrent que la fluidité de la coque joue un rôle majeur dans la modulation de l'activité des Pgp. Ils confirment que l'activité des Pgp est fortement influencée par le microenvironnement local, en particulier les stérols, comme observé dans certains modèles de vertébrés. Ainsi, les barrières de coques des oeufs pourraient jouer un rôle actif dans le transport des xénobiotiques.
\end{abstract}

*Corresponding author: Mickael.riou@inra.fr; mickael.riou@inrae.fr

${ }^{\mathrm{a} C A P F}$ : Membre du Consortium Anti-Parasitaires et Fongiques.

${ }^{\mathrm{b}}$ INRAE, Laboratoire de Cytométrie en Flux, Centre de Recherche Val de Loire, 37380 Nouzilly, France.

${ }^{\mathrm{c}}$ Directeur de Recherche honoraire de l'UMR-1282. 


$\begin{array}{ll}\text { Abbreviations } \\ \text { ABC } & \text { ATP-binding cassette } \\ \text { ATP } & \text { Adenosine TriPhosphate } \\ \text { DPH } & \text { 1,6-DiPhenyl-1,3,5-Hexatriene } \\ \text { HcR } & \text { Haemonchus contortus Resistant } \\ \text { HcS } & \text { Haemonchus contortus Susceptible } \\ \text { I// } & \text { Parallel intensity } \\ \text { I } \perp & \text { Perpendicular intensity } \\ \text { MbCD } & \text { Methyl-beta-CycloDextrin } \\ \text { MDR } & \text { MultiDrug Resistance } \\ \text { Pgp } & \text { P-glycoprotein } \\ \text { R123 } & \text { Rhodamine 123 } \\ \text { TBZ } & \text { ThiaBendaZole }\end{array}$

\section{Introduction}

Gastrointestinal nematodes include Haemonchus contortus, a highly pathogenic parasite infecting small domestic ruminants $[25,64,80]$. The prophylactic treatment of parasitic gastroenteritis relies mainly on the use of anthelmintics. However, the efficacy of anthelmintics against nematodes is compromised by the emergence of resistant parasites [40, 42, $44,60]$. Resistance to all groups of anthelmintics (benzimidazoles, imidazothiazoles, tetrahydropyrimidines and avermectins) has been observed in many studies [40, 44, 65]. Anthelmintic resistance involves several cellular mechanisms. Both specific anthelmintic resistance, for example mutation of $\beta$-tubulin, the target of thiabendazole [5, 41, 42], and nonspecific mechanisms have been described. In eukaryotes, the MDR genes and MDR protein activity are responsible for the development of resistance to drugs in tumour cells [1, 37, 43, 72]. The MDR system includes P-glycoprotein membrane "pumps" (Pgps) and multidrug resistance-associated proteins (MRP). These two transmembrane proteins are members of the ATP-binding cassette (ABC) superfamily of transporters, playing key roles in the transport of xenobiotics $[1,36,71]$.

Eukaryote cells are protected against chemical attack by their plasma membranes [73]. Many drugs and other xenobiotic molecules are lipophilic and enter the cell membranes primarily by passive diffusion ("passive influx"), which depends on solubilisation in lipids [50]. Then, xenobiotics that accumulate in the membranes are supported by membrane transporters $[1,83]$. The transport of xenobiotics thus depends on both the hydrophobicity of cell membranes and on the activity of membrane pumps [10, 11, 59]. These pumps have been implicated in cellular detoxification processes in various eukaryotic systems [3]. They are modulated by the membrane environment $[9,50,56,58]$. Among these pumps, the overexpression of Pgp confers resistance to xenobiotics in many biological systems, mainly in tumour cells resistant to chemotherapy but also in nematodes resistant to anthelmintics [2, 18, 28].

Transmembrane transport of drugs is modulated by the biochemical composition of the membrane. Qualitative or quantitative changes in membrane lipids modify the properties of cell membranes [58]. Lipids, including cholesterol and phospholipids, play an important role in the passive diffusion of xenobiotics and Pgp activity [17, 68]. Changes in membrane properties directly affect the accessibility of xenobiotic molecules to Pgp. Moreover, cholesterol interacts with phospholipids and proteins, stabilising their movement in the membrane [73] and affecting the activity of many membrane proteins, including receptors, channels, and Pgp [6, 38, 76]. Membrane properties are altered by movements of molecules that determine fluidity, and this depends largely on cholesterol concentration in vertebrate cells [39, 74]. Riou et al. and Rothnie et al. reported significant modulations of Pgp activity, respectively, in tumour cells and nematode isolates after an experimental decrease in cholesterol content [66, 70]. Riou et al. showed that the increase in resistance to anthelmintics observed during egg embryonation resulted from changes in Pgp activity in response to alterations in the membrane environment [67]. However, the biochemical/biophysical mechanisms underlying these effects remain unclear [66, 67]. Hypotheses for a role of membrane fluidity to explain these observations have been suggested [13, 21, 39].

In contrast to other eukaryotes, nematodes make use of structures other than plasma membranes, eggshells for eggs, and cuticles for later stages, which provide an additional external protective layer [35, 50]. Eggshells and cuticles are highly complex structures. Eggshells are thirty times thicker than cell membranes and have a different biochemical composition. They comprise three layers: an external vitelline layer, a medial chitinous layer, and a basal lipid/protein layer [35]. Membrane proteins have been identified in these barriers. They include active Pgp-like pumps, which are involved in the transport and elimination of lipophilic drugs, such as the anthelmintic ivermectin [46, 47].

In this study, we examine the relationship between Pgp number and activity, resistance to anthelmintics, and eggshell cholesterol content and fluidity in Haemonchus contortus nematode eggs showing different degrees of resistance to anthelmintics. The effects on fluidity of changes in the cholesterol content of eggshells were estimated by measurement of fluorescence anisotropy (FA) which is inversely proportional to membrane fluidity $[39,74,75]$. The consequences of these changes on Pgp activity were assessed by specific mAb staining, measurements of rhodamine 123 (R123) transport, and resistance to anthelmintics (thiabendazole). Four $H$. contortus (Hc) isolates were studied: two susceptible (HcS) and two resistant (HcR) isolates.

\section{Materials and methods Ethics}

All experiments were conducted in accordance with EU guidelines and French regulations (Directive 2010/63/EU, 2010; Rural Code, 2018; Decree No. 2013-118, 2013). All experimental procedures were evaluated and approved by the Ministry of Higher Education and Research (APAFIS\#00219.02 Notification-1). Procedures involving sheep were evaluated by the ethics committee of the Val de Loire (CEEA VdL, committee number 19) and took place at the INRAE Experimental Infection Platform PFIE (UE-1277 PFIE, INRAE Centre de Recherche Val de Loire, Nouzilly, France, https://doi. org/10.15454/1.5535888072272498e12). 


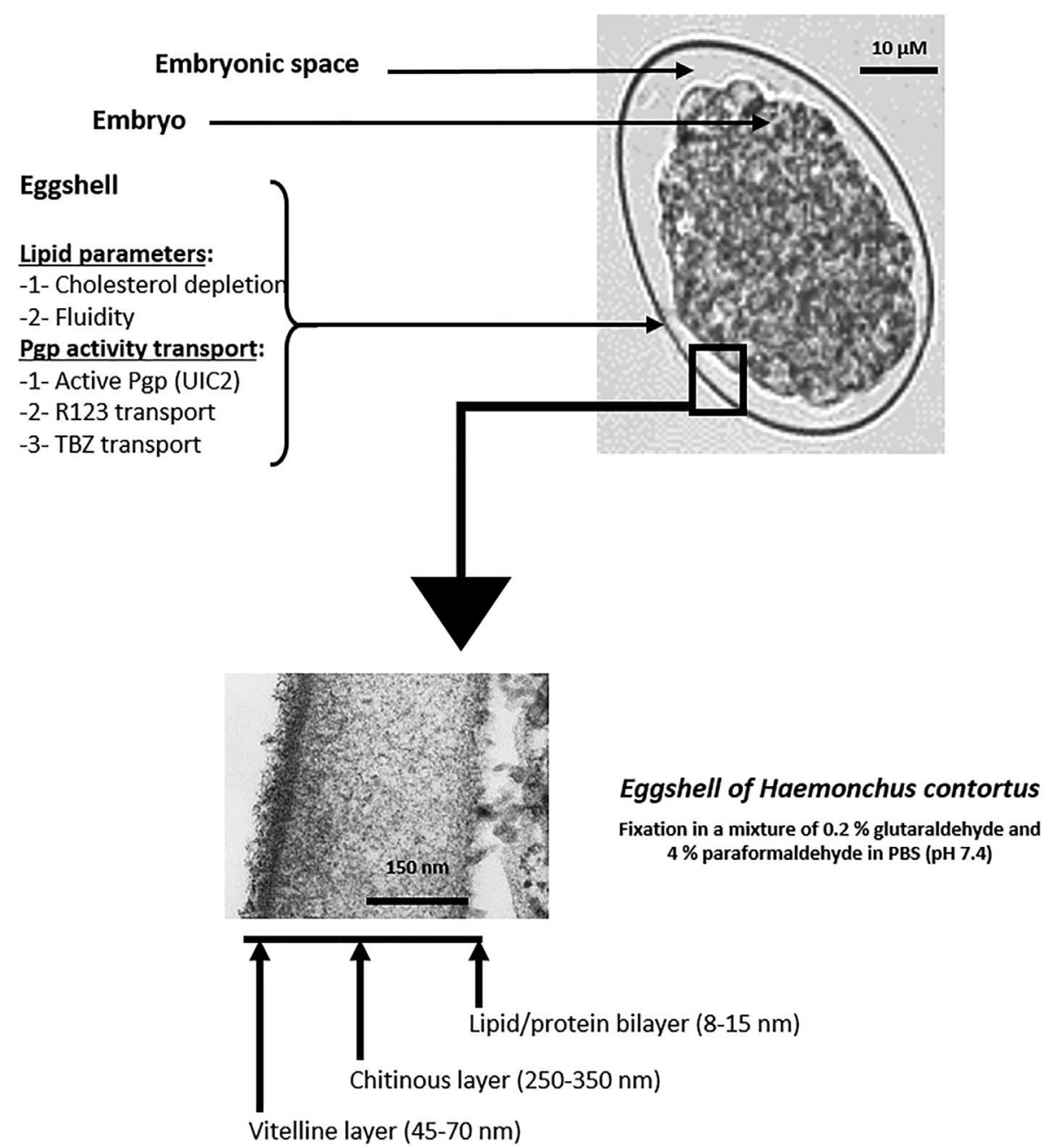

Figure 1. Biological model: Haemonchus contortus egg and eggshell.

\section{Parasites and animals}

Four H. contortus $(\mathrm{Hc})$ isolates were studied: two susceptible $(\mathrm{HcS})$ isolates (HcS-WB for "Weybridge", UK and HcS-Ca for "Canada") and two resistant (HcR) isolates (HcR-G for "Guadeloupe" resistant to benzimidazoles and ivermectin and tolerant to moxidectin and HcR-WR for "White River", South Africa, (resistant to benzimidazoles and ivermectin). Eggs (Fig. 1) were isolated from faeces. Three-month-old male "Ile de France-Charolais" lambs fed with hay and cereals were infected with $6000 \mathrm{H}$. contortus infective larvae (L3) from each isolate. The experiments comply with the current French laws on animal experimentation.

\section{Cholesterol depletion}

Methyl-beta-CycloDextrin $(\mathrm{M} \beta \mathrm{CD}$, Sigma-Aldrich, SaintQuentin, France) was used to deplete cholesterol from eggs. In solution, the $\mathrm{M} \beta \mathrm{CD}$ cavity is occupied by water molecules. This creates a state of unfavourable energy due to polar-apolar interactions. Water molecules are therefore easily replaced by less polar molecules, such as membrane cholesterol, toward which $\mathrm{M} \beta \mathrm{CD}$ has strong affinity. In addition, the cholesterol dissolved in priority in the hydrophobic cavity of the $\mathrm{M} \beta \mathrm{CD}$ $[15,51]$. Eggs were incubated four times for $1 \mathrm{~h}$ each with shaking process, in $2.25 \mathrm{mM} \mathrm{M} \beta \mathrm{CD}$ dissolved in deionised water [66]. The eggs were washed with deionised water between incubations.

Egg viability after $\mathrm{M} \beta \mathrm{CD}$ treatment was checked using egg hatch assays. After the last washing, 2500 eggs were incubated with $150 \mu \mathrm{L}$ of deionised water for $48 \mathrm{~h}$ at $22{ }^{\circ} \mathrm{C}$.

Cholesterol and phospholipid concentrations in eggs were estimated before and after M $\beta C D$ treatment [66]. Total lipids were extracted from 200,000 eggs ground in chloroform/ methanol solution (v/v; VWR International, Pessac, France). Total cholesterol concentration was determined by the cholesterol oxidase method, RTU Kit, BioMérieux, Marcy-l'Étoile, France.

The total phospholipid concentration was determined by the phospholipid hydrolase method (PAP150 Kit, BioMérieux, Marcy-l'Etoile, France). The intensity of pink colouration, after enzymatic transformation of phospholipids in quinoneimine, 


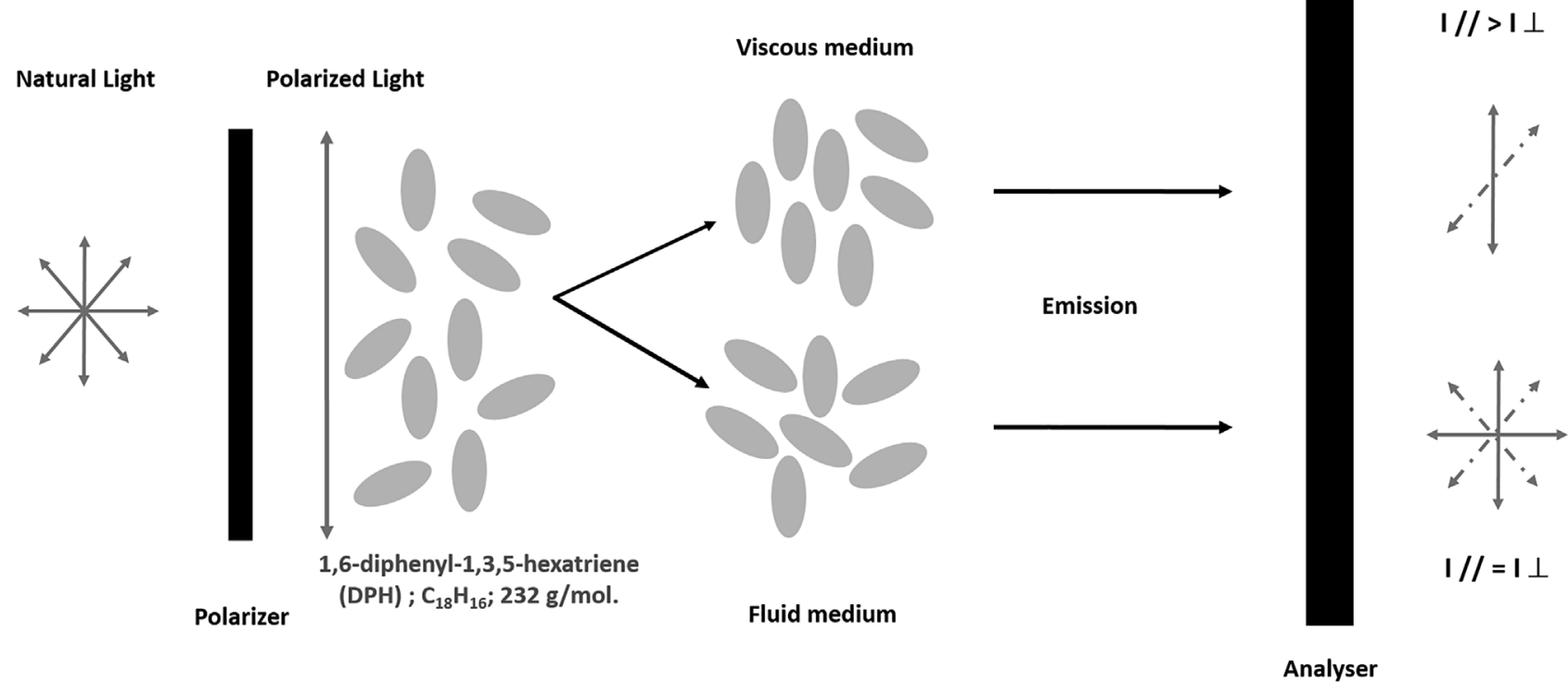

Figure 2. Physical principle of anisotropy measures (membrane fluidity) after incorporation of the 1,6-diphenyl-1,3,5-hexatriene (DPH) probe with a dual channel PTI Quanta Master Spectrofluorimeter (PTI, Monmouth Junction, NJ, USA). I//: parallel intensity; $I \perp$ : perpendicular intensity.

was measured by absorbance at $505 \mathrm{~nm}$. The phospholipid concentration (ng/egg) was deduced from a calibration curve using a reference phospholipid solution.

\section{Estimation of membrane fluidity}

Membrane fluidity was estimated by fluorescence anisotropy (FA) measurements after labelling eggs with the fluorescent lipophilic probe 1,6-diphenyl-1,3,5-hexatriene (DPH, Sigma-Aldrich, Saint-Quentin, France). This probe was readily incorporated into the membrane bilayers. FA is inversely proportional to membrane fluidity. FA values close to 0.362 and more correspond to a highly organised medium and thus to very low fluidity, while FA values close to 0.100 correspond to a very fluid lipid organization, and thus to high membrane fluidity.

Optimal contact time and DPH concentration for analysing egg membrane fluidity were determined in preliminary experiments using the HcR-G isolate. DPH concentrations from $1 \times 10^{-7} \mathrm{M}$ to $1 \times 10^{-4} \mathrm{M}$ diluted in PBS were prepared from a DPH $2 \times 10^{-3} \mathrm{M}$ stock solution in tetrahydrofuran (THF; final, Sigma-Aldrich, Saint-Quentin, France). A bell-shared curve was obtained for anisotropy plotted against DPH concentration, with a maximum at $1 \times 10^{-6} \mathrm{M}$. To measure the anisotropy into eggshell, the optimal fluorescent DPH concentration at $1 \times 10^{6} \mathrm{M}$ was chosen for this study and as described in other cellular models. This concentration, used in other cellular models, was chosen in subsequent experiments. Four contact times $(15,30,45$, and $60 \mathrm{~min})$ were compared for two DPH concentrations $\left(1 \times 10^{-6} \mathrm{M}\right.$ and $\left.1 \times 10^{-4} \mathrm{M}\right)$. For 15 and 30 min contact times, anisotropy was unchanged, but lower anisotropy values were obtained for 45 and $60 \mathrm{~min}$ contact times.

We incubated 30,000 eggs in $3 \mathrm{~mL}$ of a fresh dilution of $\mathrm{DPH}$ in PBS before and after M $\mathrm{BCD}$ treatment. In these conditions, the probe was found primarily in the egg membrane as it did not have enough time to diffuse more widely. A temperature of $20{ }^{\circ} \mathrm{C}$ was used as this is the optimum temperature for parasite development in vitro. Additionally, this was the temperature used for the various treatments previously shown to affect parasite resistance.

The fluorescence anisotropy regression coefficient $(r)$ was calculated from fluorescence intensity measurements with a dual channel PTI Quanta Master Spectrofluorimeter (PTI, Monmouth Junction, NJ, USA), through crossed polarizing filters. Felix software ${ }^{\circledR}$ provided a macro-command for the calculation of anisotropy. The anisotropy coefficient $r$ was calculated as follows:

$$
r=(I / /-g I \perp) /(I / /+2 g I \perp)
$$

where parallel $(I / /)$ and perpendicular $(I \perp)$ intensity were the respective emission fluorescence intensities through parallel and perpendicular filters to a vertical polarised excitation beam $\left(\lambda_{\text {excitation }}=365 \mathrm{~nm}\right.$ and $\left.\lambda_{\text {emission }}=430 \mathrm{~nm}\right)$. The $\mathrm{g}$ factor is a correction factor calculated before each batch of measurements (Fig. 2). With the number of eggs used in each test, no significant light scattering occurred due to autofluorescence of eggs in PBS solution [21, 39, 74, 75].

\section{Pgp activity assays}

\section{Identification of active Pgp}

The presence of Pgp in active conformation was determined by UIC2 $\mathrm{mAb}$ staining (Immunotech, Marseille, France), estimated by flow cytometry using a MoFLo ${ }^{\mathrm{TM}}$ cell sorter (Beckman Coulter, Fort Collins, CO 80825, USA) before and after $2.25 \mathrm{mM} \mathrm{M} \beta \mathrm{CD}$ treatment. The UIC2 mAbs recognise an epitope associated with a specific active Pgp conformation 
induced by drugs. Briefly, eggs were pre-treated with PBS plus BSA $(2 \mathrm{mg} / \mathrm{mL})$ and decanted for $10 \mathrm{~min}$. They were further washed in $1 \mathrm{~mL}$ PBS. The eggs were stained for $90 \mathrm{~min}$ at room temperature by adding $35 \mu \mathrm{L}$ of pure UIC 2 mAb coupled with phycoerythrin (UIC2-PE). They were washed twice with $3 \mathrm{~mL}$ PBS and suspended in $1 \mathrm{~mL}$ PBS. The intensity of orange fluorescence was immediately measured by flow cytometry with a 580/30 nm band pass filter. Control eggs were similarly treated with isotypic IgG2a mAbs coupled with PE (IgG2a-PE, U7.27 clone, Immunotech, Marseille, France). The fluorescence means were expressed in arbitrary units (au) for the four isolates. The positive egg populations were obtained by histogram subtractions [29, 30, 32, 34].

\section{Transport activity}

Xenobiotic transport was determined by rhodamine 123 accumulation (R123 Sigma-Aldrich, Saint-Quentin, France), a fluorescent substrate specific for Pgp pumps, before and after M $\beta C D$ treatment. R123 absorptive transport occurs primarily by the paracellular route, whereas R123 secretory transport involves influx across membrane mediated solely by a saturable process followed by apically directed efflux via Pgp (fixation on the $R$ site). R123 is therefore a good model for characterising the transport of drugs such as anthelmintics (such as thiabendazole, levamisole, and ML) by Pgp.

In all, 30,000 eggs were incubated with $1 \mathrm{~mL}$ of $\mathrm{R} 123$ $(0.5 \mu \mathrm{g} / \mathrm{mL})$ at room temperature for $30 \mathrm{~min}$ and then washed with deionised water. The intensity of green fluorescence was immediately measured by flow cytometry on a MoFLo ${ }^{\mathrm{TM}}$ cell sorter (Beckman Coulter, Fort Collins, CO 80825, USA), with a 530/40 nm band pass filter. The results were expressed in arbitrary units (AU) calculated as the difference between the fluorescence of eggs without R123 and the fluorescence of eggs stained with R123, thus eliminating any native green fluorescence, which differed between isolates [12, 30, 31, 66, 69].

\section{Resistance to thiabendazole by egg hatch assays after MBCD treatment}

A total of 2500 eggs/sample were treated, as described previously. The eggs were incubated for $48 \mathrm{~h}$ at $22{ }^{\circ} \mathrm{C}$ with concentrations of thiabendazole ranging from 0.02 to $0.08 \mu \mathrm{g} / \mathrm{mL}$ for the susceptible isolates, and from 0.24 to $1.26 \mu \mathrm{g} / \mathrm{mL}$ for the resistant ones [4, 7, 29]. Hatching rates were compared to those of control eggs treated with deionised water or thiabendazole only.

\section{Statistical analyses}

Three replicates were performed for each treatment and for each factor studied. Statistical analyses were performed using GraphPad Prism software, version 5.0 (GraphPad, San Diego, CA, USA). A two-way ANOVA analysis was performed to show the effects of the treatments on the measured parameters, taking into account the parasitic isolate effect. In parallel, non-parametric statistical tests (Mann-Whitney $U$ tests) were carried out, followed by Bonferroni tests.
Table 1. Hatching rates of eggs in water (control) or after $\mathrm{M} \beta \mathrm{CD}$ treatment $(2.25 \mathrm{mM})$. The $\mathrm{M} \beta \mathrm{CD}$ treatment had no toxic effect. Percent hatching rates (means of three egg hatch assays) of treated eggs weighted according to the percent hatching rate in control samples.

\begin{tabular}{lcccc}
\hline & HcS-WB & HcS-Ca & HcR-WR & HcR-G \\
\hline Untreated eggs & 100 & 100 & 100 & 100 \\
M $\beta C D(2.25 \mathrm{mM})$ & 106.5 & 98.7 & 105.3 & 110.5 \\
\hline
\end{tabular}

HcS-WB: Haemonchus contortus susceptible Weybridge, HcS-Ca: Haemonchus contortus susceptible Canada, HcR-WR: Haemonchus contortus resistant White River, and HcR-G: Haemonchus contortus resistant Guadeloupe.

Principal component analysis (PCA) and linear regressions were performed using XLstat software, version 7.5.2. (Addinsoft, Paris, France).

\section{Results \\ M $\beta C D$ treatment altered cholesterol content of eggs}

$\mathrm{M} \beta \mathrm{CD}$ treatment had no toxic effects on parasite development for all isolates (Table 1).

Before treatment with $\mathrm{M} \beta \mathrm{CD}$, cholesterol content was significantly higher in the two susceptible isolates than in the two resistant isolates (Fig. 3A, $p<0.05$ ). M $\beta \mathrm{CD}$ treatment significantly decreased the cholesterol concentration of eggs for the HcS-WB, HcS-Ca, and HcR-WR isolates $(p<0.05)$, but the effect was not significant for the HcR-G isolate (means of lipid concentration $\pm S D$ for three measurements). After the M $\beta C D$ treatment, total phospholipid content was not modified significantly for the HcS-WB, HcS-Ca, and HcR-G isolates, except for the HcR-WR (Fig. 3B, $p<0.05$ ). The phospholipid concentrations before treatment were similar between the four isolates.

\section{Egg anisotropy depended on changes in the lipid content}

Before treatment with $\mathrm{M} \beta \mathrm{CD}$, egg anisotropy was significantly higher in the susceptible HcS-WB isolate than in the other three isolates $(p<0.05)$. M $\beta C D$ treatment significantly decreased fluorescence anisotropy (FA) of eggs for the HcS-WB, HcS-Ca, and HcR-WR isolates $(p<0.05)$, but the effect was not significant for the HcR-G isolate (Fig. 3C).

\section{Pgp activity}

\section{The number of "active" Pgps after cholesterol depletion}

Untreated susceptible nematode isolates were significantly less stained by UIC2 staining than untreated resistant isolates (Fig. 4A, $p<0.05$ ). M $\beta C D$ treatment increased UIC2 staining significantly for the HcS-WB, HcS-Ca, and HcR-WR isolates (Fig. 4A, $p<0.05$ ). 
A

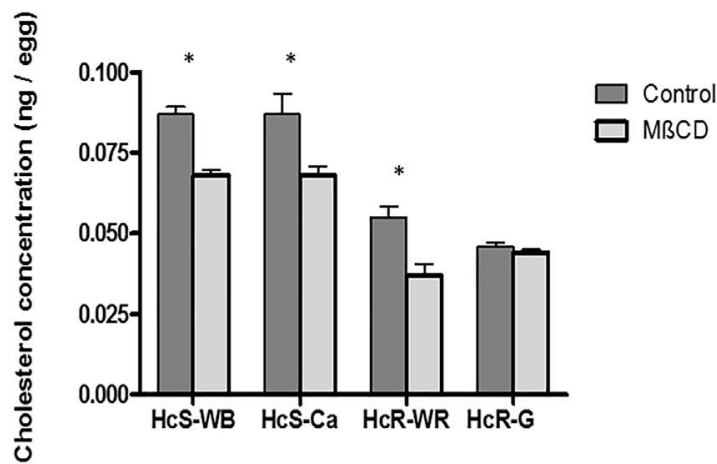

B
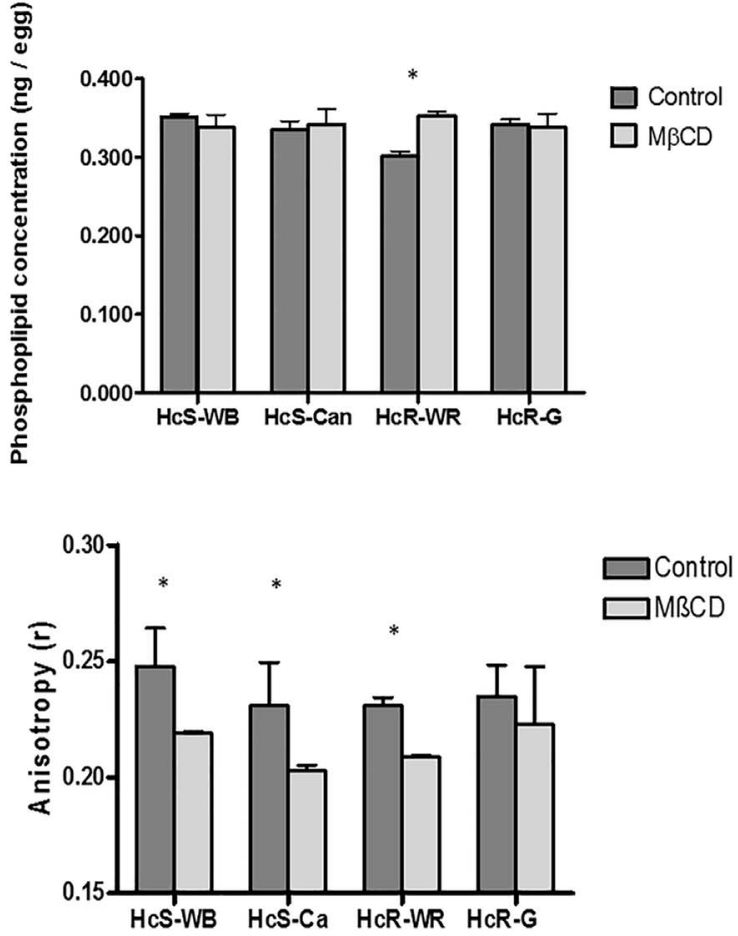

Figure 3. (A) Measurement of cholesterol content in nematode eggs before and after $\mathrm{M} \beta \mathrm{CD}(2.25 \mathrm{mM})$ treatment. The cholesterol content of the two susceptible isolates was higher than that of the two resistant isolates $(p<0.05)$. Treatment of eggs significantly decreased the cholesterol concentration in eggs, except for the HcR$\mathrm{G}$ isolate $(p<0.05)$. (B) Measurement of phospholipid content in nematode eggs before and after M $\beta C D$ (2.25 mM) treatment. The phospholipid content was not modified by the $\mathrm{M} \beta \mathrm{CD}$ treatment. (C) Measurement of anisotropy after alterations in eggshells. M $\beta C D$ treatment decreased the anisotropy significantly in HcS-WB, HcS$\mathrm{Ca}$, and HcR-WR isolates $(p<0.05)$. Means of lipid concentrations $(M \pm S D$ for three measurements). *Significant effect $(p<0.05)$. Symbols: (grey rectangles) control eggs and (black rectangles) M $\beta C D$ treatment. HcS-WB: Haemonchus contortus susceptible Weybridge, HcS-Ca: Haemonchus contortus susceptible Canada, HcR-WR: Haemonchus contortus resistant White River, and HcR-G: Haemonchus contortus resistant Guadeloupe.

\section{Pgp activity (efflux) after cholesterol depletion}

Untreated susceptible nematode isolates accumulated significantly less R123 than the untreated resistant isolates (Fig. 4B, $p<0.05$ ). The M $\beta C D$ treatment only significantly
A

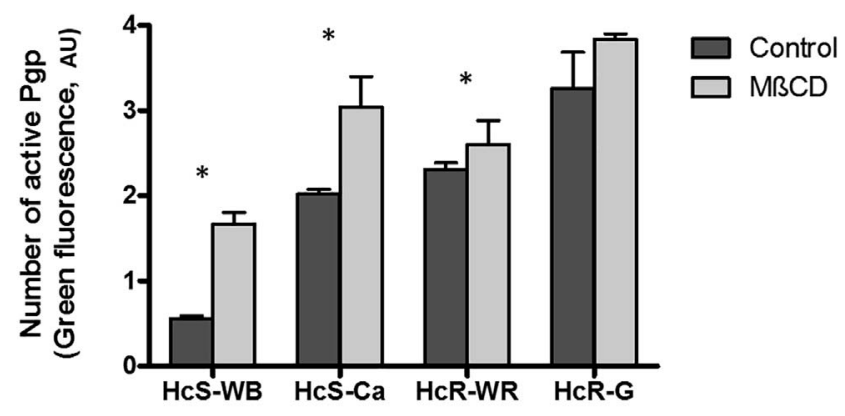

B

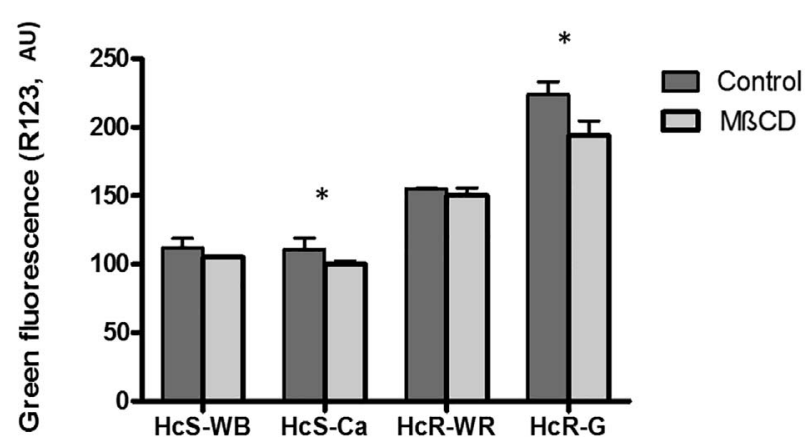

Figure 4. Quantification and measurement of Pgp activity in nematodes after $\mathrm{M} \beta C D(2.25 \mathrm{mM})$ treatment. (A) Determination of active Pgp in nematode eggs before and after M $\beta C D(2.25 \mathrm{mM})$ treatment by UIC $2 \mathrm{mAb}$ staining. $\mathrm{M} \beta \mathrm{CD}$ treatment increased the UIC2 staining significantly for the HcS-WB, HcS-Ca, and HcR-WR isolates after $\mathrm{M} \beta \mathrm{CD}(2.25 \mathrm{mM})$ treatment. Mean fluorescence intensity $(M \pm S D$ for three measurements). *Significant effect $(p<0.05)$. (B) Untreated susceptible nematode isolates accumulated significantly less R123 than untreated resistant isolates $(p<0.05)$. Significant difference of R123 accumulation between susceptible and resistant isolates $(p<0.05)$. M $\beta C D$ treatment decreased R123 accumulation, significantly for the $\mathrm{HcS}-\mathrm{Ca}$ and $\mathrm{HcR}-\mathrm{G}$ isolates $(p<0.05)$. Mean fluorescence intensity $(M \pm S D$ for three measurements) was estimated from the difference between the native green fluorescence of eggs and that of eggs stained with R123. *Significant effect $(p<0.05)$. Symbols: (grey rectangles) control eggs and (black rectangles) $\mathrm{M} \beta \mathrm{CD}$ treatment. HcS-WB: Haemonchus contortus susceptible Weybridge, HcS-Ca: Haemonchus contortus susceptible Canada, HcR-WR: Haemonchus contortus resistant White River, and HcR-G: Haemonchus contortus resistant Guadeloupe.

decreased R123 accumulation in the $\mathrm{HsC}-\mathrm{Can}$ and $\mathrm{HcR}-\mathrm{G}$ isolates (Fig. 4B, $p<0.05$ ).

\section{Resistance to thiabendazole increased after cholesterol depletion}

$\mathrm{M} \beta \mathrm{CD}$ treatment increased the $50 \%$ lethal dose $\left(\mathrm{LD}_{50}\right)$ of thiabendazole (TBZ) (Fig. 5) for the four isolates, but the effect was significant only for the two resistant isolates (HcR-WR and HcR-G, $p<0.05$, Fig. 5).

\section{Multi-parametric analyses of Pgp activity}

Principal component analysis (PCA) enabled us to establish a relationship between the different parameters. The Bartlett 


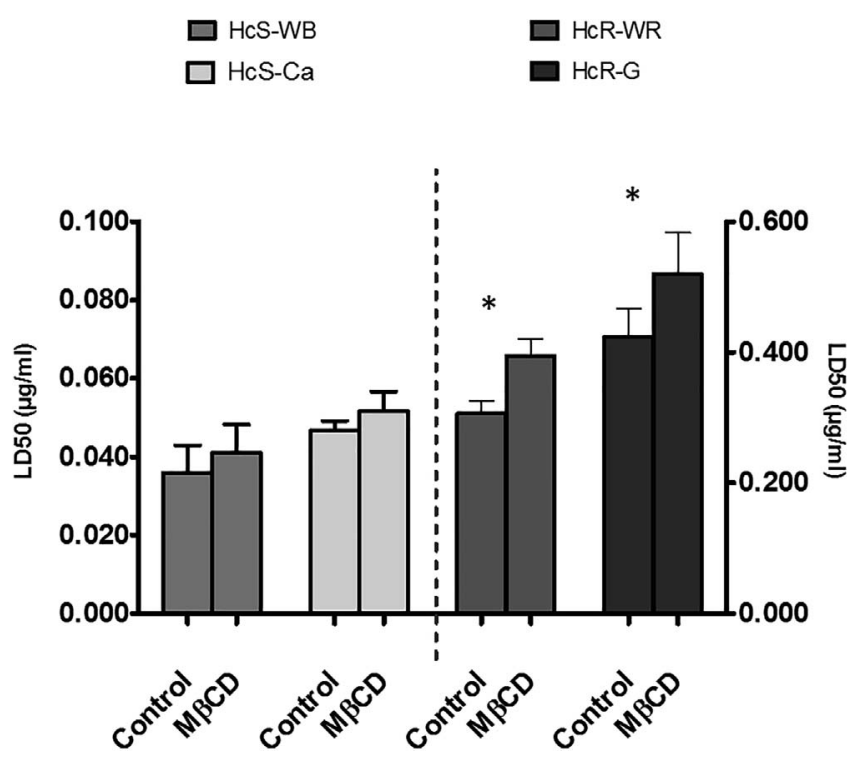

Figure 5. Effect of methyl- $\beta$-cyclodextrin $(\mathrm{M} \beta \mathrm{CD}, 2.25 \mathrm{mM})$ on resistance to thiabendazole (lethal dose $50 \%$ or $\mathrm{LD}_{50}$ ), for each isolate. $\mathrm{M} \beta C D$ treatment increased the $\mathrm{LD}_{50}$ of thiabendazole (TBZ) but the effect was significant only for the two resistant isolates $(p<0.05)$. The values reported are means $\pm S D$ of three replicates. *Significant effect $(p<0.05)$. Symbols: (grey rectangles) control eggs and (black rectangles) $\mathrm{M} \beta \mathrm{CD}$ treatment. HcS-WB: Haemonchus contortus susceptible Weybridge, HcS-Ca: Haemonchus contortus susceptible Canada, HcR-WR: Haemonchus contortus resistant White River, and HcR-G: Haemonchus contortus resistant Guadeloupe.

sphericity test rejects the null hypothesis of the absence of correlation between the variables $(p<0.0001)$.

Correlation analyses (Pearson test, Table 2) identified the following relationships:

- UIC2 staining, R123 accumulation and TBZ resistance are significantly correlated to cholesterol content of eggs ( $p$ respectively $<0.04,<0.03$ or $<0.004)$;

- the number of active Pgps was significantly correlated with R123 accumulation $(p<0.005)$ and TBZ resistance $(p<0.008)$;

- R123 accumulation was significantly correlated with TBZ resistance $(p<0.007)$;

- no correlation was found between anisotropy and the four other parameters.

Figure 6A shows the distribution of isolates and the relationships between parameters that were explained at
94\% by two axes (F1 and F2). The F1 axis is mainly linked to the cholesterol content, the number of active Pgps, R123 transport, and TBZ resistance. Cholesterol content varied in a way opposite to the other three parameters. The anisotropy was linked to the F2 axis. The F1 axis thus allowed us to distinguish two groups, resistant isolates and susceptible isolates, while the F2 axis separated the control group from the group treated with $\mathrm{M} \beta \mathrm{CD}$. The cholesterol content, the number of active Pgps, and R123 accumulation were highly discriminant variables for each isolate (Fig. 6B).

Several significant linear regressions were established (Table 3) between cholesterol and either Pgp activity (UIC2 or R123 accumulation) or TBZ resistance, and between Pgp activity (UIC2 or R123 accumulation) and TBZ resistance.

\section{Discussion}

We previously suggested that a reduction in cholesterol concentrations may lead to changes in the organisation of membrane lipids and possibly affect the diffusion of lipophilic molecules such as R123 or anthelmintics in eggshells. Consistent with this hypothesis and with the usual observations made on plasma membranes, we observed in the present study an increase in eggshell fluidity after cholesterol depletion by $\mathrm{M} \beta \mathrm{CD}$ in both susceptible and resistant nematodes. Therefore, cholesterol depletion seems to modify the organisation of lipid eggshells. Cholesterol depletion induces an increase in the fluidity of the eggshell of nematode, like in other conventional membrane systems [15, 26, 82].

In the present work, and for the first time, we showed that resistance of nematodes to anthelmintics increased following cholesterol depletion, which could be attributed to fluidification of the eggshell and an increase in Pgp activity. We investigated here cellular and molecular interactions between (1) cholesterol concentrations in eggshells, (2) membrane fluidity, (3) active Pgp estimated by staining with UIC2 mAbs, (4) efflux transport by measuring the accumulation of a specific Pgp fluorescent substrate (R123), and (5) resistance to anthelmintics with thiabendazole. A very strong relationship between the five parameters studied shows a very clear differentiation between susceptible isolates and resistant isolates. Therefore, the resistance state can be defined by the following parameters: cholesterol (biological membranes)/UIC2 (active Pgp)/R123 (Pgp activity). This relationship between these parameters has been observed in other nematode species (Caenorhabditis elegans and Cylicocyclus elongatus) and other pathogens such as bacteria and fungi $[6,28,45,48,49,66]$. This study was

Table 2. Matrix of correlation of five parameters (cholesterol content, anisotropy, R123 accumulation, UIC2 staining, and resistance to thiabendazole [TBZ]) obtained by principal component analysis for each isolate.

\begin{tabular}{|c|c|c|c|c|c|}
\hline Parameters & Cholesterol content & Anisotropy & UIC2 staining & R123 accumulation & Resistance to TBZ \\
\hline Cholesterol content & 1 & & & & \\
\hline Anisotropy & 0.406 & 1 & & & \\
\hline UIC2 staining & -0.761 (a) & -0.207 & 1 & & \\
\hline R123 accumulation & -0.738 (a) & 0.202 & 0.876 (a) & 1 & \\
\hline Resistance to TBZ & -0.895 (a) & -0.063 & 0.844 (a) & 0.906 (a) & 1 \\
\hline
\end{tabular}

a: Significant effect $(p<0.05)$. 
A

Parasite isolates (axes F1 et F2: $94.32 \%$ )

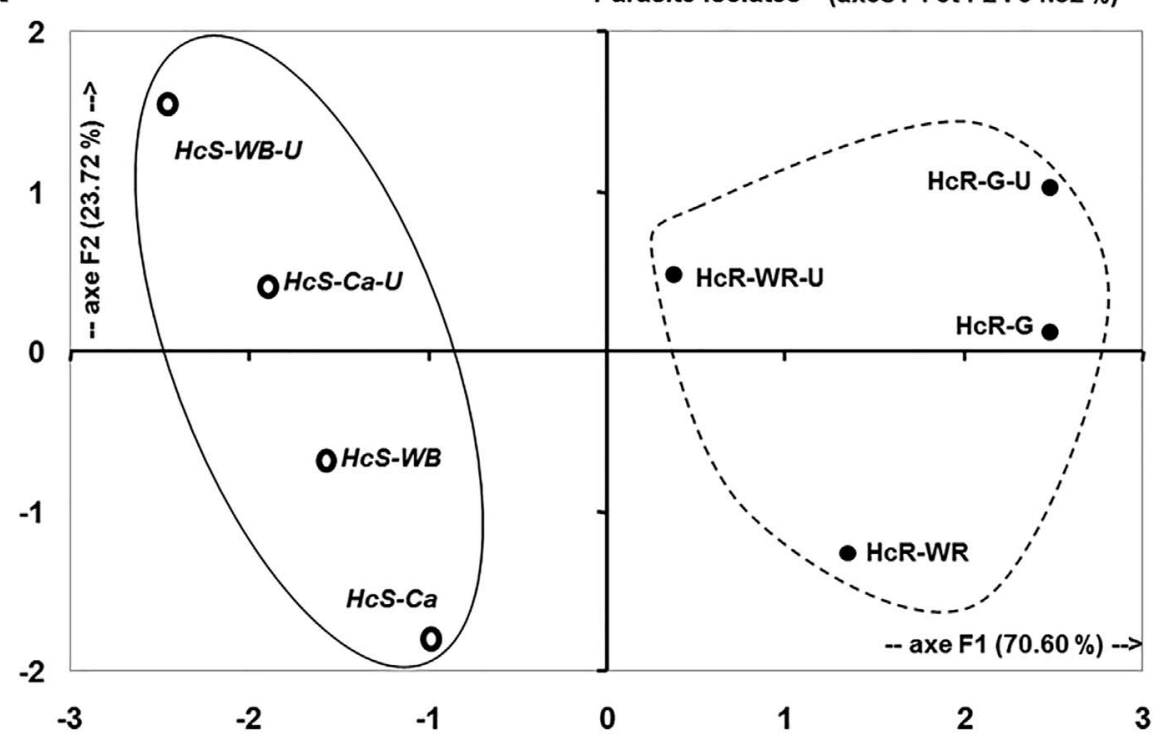

B

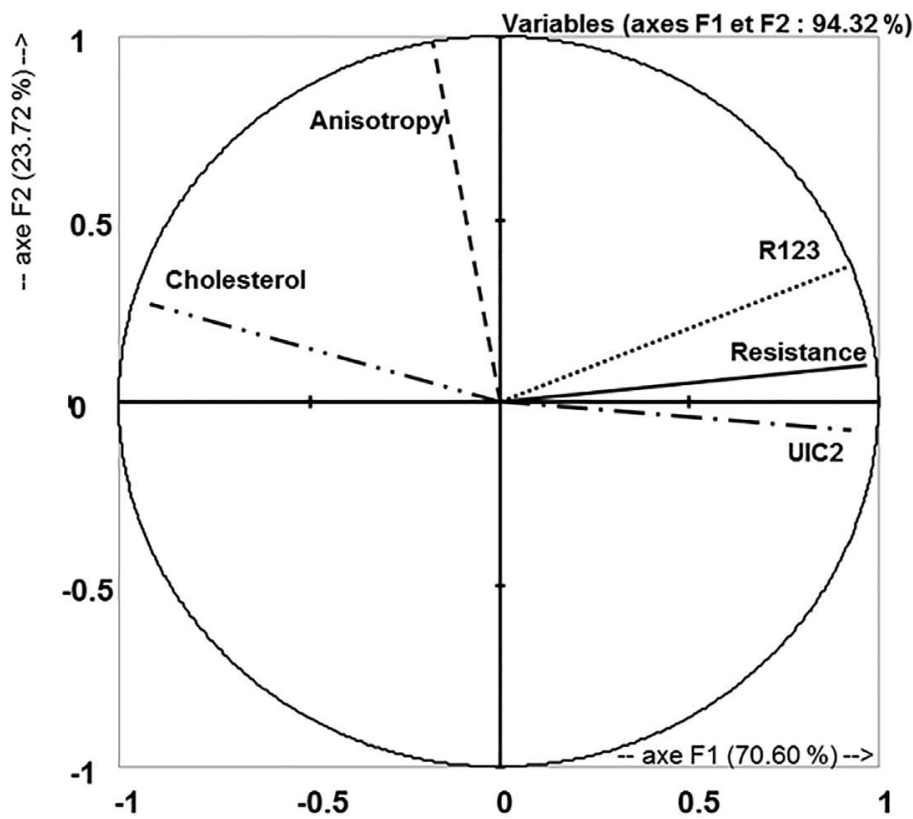

Figure 6. Multiparametric analyses of Pgp activity and the lipid environment in Haemonchus contortus nematode eggs before and after M $\beta C D(2.25 \mathrm{mM})$ treatment. HcS-WB: Haemonchus contortus susceptible Weybridge, HcS-WB-U: Haemonchus contortus susceptible Weybridge Untreated, HcS-Ca: Haemonchus contortus susceptible Canada, HcS-Ca-U: Haemonchus contortus susceptible Canada Untreated, HcR-WR: Haemonchus contortus resistant White River, HcR-WR-U: Haemonchus contortus resistant White River Untreated, HcR-G: Haemonchus contortus resistant Guadeloupe, and HcR-G-U: Haemonchus contortus resistant Guadeloupe Untreated.

the first to measure membrane fluidity in nematodes and to establish relationships with cholesterol content, and confirmed the results obtained in other eukaryote models [20, 39, 54, 81].

We recently found that modulation of Pgp activity in nematodes can be obtained by approaches very similar to those used for other eukaryote models [32, 33, 66]. Studies on vertebrate cells showed new means for the modulation of Pgp activity after modifications of cholesterol concentrations that alter the membrane environment. The experimental change in cholesterol content was obtained using a cholesterol acceptor, methyl- $\beta$-cyclodextrin. $\beta$-cyclodextrins have high affinity for lipids [15]. Moreover, the methyl form (M $\beta C D)$ preferentially extracts cholesterol from membrane cells [15, 80, 81]. We confirmed that cholesterol depletion by M $\beta C D$ treatment $(2.25 \mathrm{mM} \mathrm{M} \beta \mathrm{CD}$ concentration four times over $60 \mathrm{~min}$ ) did not alter the viability of $H$. contortus eggs. However, it altered their cholesterol content, the first parameter, as previously described [66]. The depletion was enough to 
Table 3. Relationships between cholesterol content and number of Pgps in the active conformation (UIC2 antibodies), Rhodamine 123 (R123) transport, and resistance to thiabendazole (TBZ) in Haemonchus contortus eggs independently of M $\beta C D$ treatment.

\begin{tabular}{|c|c|c|c|c|c|}
\hline$X$ & $Y$ & Regression & $d f$ & $r$ & $p<$ \\
\hline Cholesterol content & Anisotropy & $Y=0.5354 x-0.0589$ & 7 & 1 & NS \\
\hline Cholesterol content & R123 accumulation & $Y=-0.0003 x+0.1061$ & 7 & 1 & 0.05 \\
\hline Cholesterol content & UIC2 staining & $Y=-0.0211 x+0.2083$ & 7 & 1 & 0.05 \\
\hline Cholesterol content & Resistance to TBZ & $Y=-0.084 x+0.0806$ & 7 & 1 & 0.01 \\
\hline R123 accumulation & Resistance to TBZ & $Y=0.0041 x-0.3557$ & 7 & 1 & 0.01 \\
\hline R123 accumulation & UIC2 staining & $Y=0.0131 x+5.0653$ & 7 & 1 & 0.01 \\
\hline Resistance to TBZ & UIC2 staining & $Y=2.8585 x+6.3059$ & 7 & 1 & 0.01 \\
\hline
\end{tabular}

NS: non-significant; $r$ : regression coefficient; $d f$ : statistic data corresponding to the degree of freedom.

change the total cholesterol content of eggs without any toxic effect on egg embryonation. This effect was similar to that obtained with a higher concentration, i.e. $75 \mathrm{mM}$ for a shorter contact time, i.e. $10 \mathrm{~min}$ [66].

The second parameter modified after $M \beta C D$ treatment is membrane fluidity, estimated by anisotropy. Changes in the biophysical properties of eggshells were evaluated as described for other models, by measuring steady-state anisotropy with a fluorescent probe, 1,6-diphenyl-1,3,5-hexatriene (DPH) incorporated into the eggshells. In vertebrate cells, DPH incorporates into the hydrocarbon core of membrane bilayers [74, 75]. Despite the complexity of the $H$. contortus model, the values obtained for eggshell anisotropy and their variations with cholesterol concentrations were similar to those observed in vertebrate cells. In $H$. contortus, we showed that the embryonation of eggs increases membrane fluidity [67]. The increase in eggshell fluidity observed during parasite development reflects changes in the organisation of lipids in the membranes, and affects the subcellular distribution of anthelmintics and their access to Pgp, thereby increasing resistance. In untreated eggs and in the total absence of embryonation, fluidity is significantly lower in the eggshells of susceptible isolates than in those of resistant isolates. In untreated and embryonated eggs, isolates did not differ significantly in eggshell fluidity or cholesterol content, as previously shown. The effect of depletion was thus less marked than that of embryonation [67]. The advantage was better controlled testing conditions. The lipid content of eggs during embryonation varied and depended on the isolate. Variations in membrane fluidity thus depend on a native difference in the eggshells (lipid composition), on the efficacy of $\mathrm{M} \beta \mathrm{CD}$ treatment, and on egg embryonation. In this work, our four parasite isolates responded significantly to $\mathrm{M} \beta \mathrm{CD}$ treatment on lipid measured parameters, except for the HcR-G isolate. Our hypothesis is that the sterol lipid composition of the HcR-G eggshell is different from the other three isolates and $\mathrm{M} \beta \mathrm{CD}$ did not have the same affinity for the sterols present in the HcR-G eggshell.

Alongside changes in the eggshell after $\mathrm{M} \beta \mathrm{CD}$ treatment, it is important to analyse the impact of treatment on the last three parameters: (i) active Pgp, (ii) the activity of transport by Pgp, and (iii) the relationship between the efflux pump and TBZ resistance [73, 74]. An increase in membrane fluidity induced by $\mathrm{M} \beta C D$ changed structural conformation of Pgps. Configuration of the membrane Pgp changes from active to very active conformation according to ATP level in the cell and alteration of lipid membranes [1, 16, 61-63]. For this last point, we showed that cholesterol depletion activates efflux pumps (Pgps).Moreover, the concentrations of membrane cholesterol goes through an optimal for the active form of Pgps [55, 68]. When Pgps are most active (optimal efflux), this activation is directly related to an increase in the transport activity of the antiparasitic, but also to an increased affinity for specific substrates such as R123 or thiabendazole. Changes in the cholesterol content of other cellular systems have been shown to affect: (a) their affinity for the substrate of transmembrane proteins such as hormonal receptors [38] or (b) the transduction of the intracellular signals $[19,43]$. In our experimental conditions, it seems that the mechanism is more likely due to a modulation of transport. We hypothesize that TBZ, a hydrophobic compound, diffused passively through lipid-rich membranes. To mimic the passive diffusion and efflux exchange of TBZ, Rhodamine R123 seems to be the right candidate. It possesses similar physicochemical properties (lipophilic molecule) compared to anthelmintics and has a Pgp binding site on the $R$ site $[12,18]$. The flow cytometric assays on the fluorescence of nematode eggs resulting from the contact with R123 allowed us to observe this mechanism more directly. Nevertheless, only a small amount of R123 is taken up passively and this process is very slow. Therefore, the fluorescence of eggs after contact with R123 was mainly representative of the activity of Pgp [31, 66]. The intensity of green fluorescence decreased significantly after $\mathrm{M} \beta \mathrm{CD}$ for the four isolates. As a result, a decrease in fluorescence after $\mathrm{M} \beta C D$ treatment might be attributed to stimulated Pgp activity resulting from a decrease in cholesterol content. R123 native transport increased with resistance in $H$. contortus isolates. Differences between susceptible and resistant isolates have mostly been attributed to the presence of higher amounts of Pgp in the resistant isolates, leading to the binding of larger numbers of R123 molecules than in susceptible isolates, such described in Kerboeuf et al. [34]. A final point that could impact the function and the regulation of Pgp in nematodes is the presence of different Pgp isoforms. In $H$. contortus, several Pgp isoform genes were identified such as Hco-pgp-3, Hco-pgp-9.2, Hco-pgp-11, and Hco-pgp-16, specifically up-regulated in parasitic life stages, suggesting potential involvement of these Pgps in the efflux of eosinophil granule products [27]. Some Pgp isoforms were involved in anthelmintic resistance mechanisms such as MDR1 or Pgp-1 [22-24], like in other pathogens or cellular lines [28, 52], and other Pgps such as Pgp-3 (MDR3) implicated in lipid transport [10, 11, 77, 78]. In our study, the different isolates may possess different pump isoforms 
(amount of protein and gene expression) with different susceptibilities towards depletion. The relationship between Pgp isoforms and membrane lipids could thus modulate Pgp activity, particularly those associated with resistance to anthelmintics, as demonstrated by Riou et al. to resistance of thiabendazole [68].

It can therefore be suggested that the solubilisation of lipophilic molecules is, as a consequence, altered and that cholesterol depletion may favour an increase in Pgp activity, accompanied by a decreased in R123 accumulation in eggs. It is difficult to determine the relative contributions of changes in the solubilisation of lipophilic molecules (R123 or anthelmintics) and transport by cellular pumps (Pgp). The mechanisms described here for the modulation of R123 transport by cholesterol, if applied to the transport of anthelmintics in nematodes may account, at least in part, for the observed changes in resistance to anthelmintics. Anthelmintics must be solubilised in membrane lipids, in which they accumulate, before they can penetrate eggs. Anthelmintics are also Pgp substrates and are eliminated by these pumps. The mechanisms of xenobiotic transport by Pgp are not fully understood, but changes in the membrane environment may be involved in regulating anthelmintic transport. The roles of the various components of lipophilic molecule transport systems (passive diffusion, active influx, and active efflux) need to be investigated further, as well as the role and production of lipids in nematodes. This knowledge may therefore make it possible to identify new targets for anthelmintics, like other targets described in recent research in order to counter multiple resistance $[8,14,46,53$, 57, 79].

\section{Conclusion}

Surprisingly, eggshells have certain biophysical properties common with the plasma membrane of vertebrate cells, but a more complex structure and biochemical composition. Eggshells appear to be more than a simple physical barrier and resemble membranes in having active biological properties. The membrane lipid composition of eggshells seems to have a significant effect on the regulation of anthelmintic transport in nematodes.

Fluidity is a complex parameter depending on many factors, including lipid composition (sterols, phospholipids, unsaturated fatty acids, etc.), and the presence of membrane proteins such as Pgp. A reduction in cholesterol content in the eggshell increased the number of active Pgps and altered TBZ solubilisation into the eggshell, and thus changed resistance to anthelmintics. The nematode egg was therefore considered a very good model for studying resistance to anthelmintics.

Acknowledgements. We would like to thank the "Région CentreVal de Loire" for funding this research. We also thank Dr. Yan Van Wyk, Dr. Gilles Aumont and Professor Roger Prichard for kindly providing the $H$. contortus isolates, as well as the research staff and the management of the PFIE, in particular Thierry Chaumeil and Maud Renouard for the careful maintenance of animals and Marie-Estelle Esnault and her team for their precious help with the bibliography. PFIE is part of EMERG' IN, the national infrastruc- ture for the control of animal and zoonotic emerging infectious diseases through in vivo investigation. We are also grateful to Mrs. Marie Fassot-Garnier for her participation in the experiments. Many thanks to Professor Claude Motta (Faculté de Médecine de Rennes), for advice on this work.

\section{Conflict of interest}

The authors declare that they have no conflicts of interest in relation to this article.

\section{References}

1. Abu-Qare AW, Elmasry E, Abou-Donia MB. 2003. A role for P-glycoprotein in environmental toxicology. Journal of Toxicology and Environmental Health, Part B Critical Reviews, 6(3), 279-288.

2. Ambudkar SV, Dey S, Hrycyna CA, Ramachandra M, Pastan I, Gottesman MM. 1999. Biochemical, cellular, and pharmacological aspects of the multidrug transporter. Annual Review of Pharmacology and Toxicology, 39, 361-398.

3. Barrett J. 1997. Helminth detoxification mechanisms. Journal of Helminthology, 71(2), 85-89.

4. Beaumont-Schwartz C, Kerboeuf D, Hubert J. 1987. Méthodes de mise en évidence de souche de strongles gastro-intestinaux resistantes aux anthelminthiques. Recueil de Médecine Vétérinaire, 163, 683-688.

5. Beech RN, Prichard RK, Scott ME. 1994. Genetic variability of the beta-tubulin genes in benzimidazole- susceptible and resistant strains of Haemonchus contortus. Genetics, 138(1), 103-110.

6. Bessa LJ, Ferreira M, Gameiro P. 2018. Evaluation of membrane fluidity of multidrug-resistant isolates of Escherichia coli and Staphylococcus aureus in presence and absence of antibiotics. Journal of Photochemistry and Photobiology B, 181, $150-156$.

7. Beugnet F, Gauthey M, Kerboeuf D. 1997. Partial in vitro reversal of benzimidazole resistance by the free- living stages of Haemonchus contortus with verapamil. Veterinary Research, 141(22), 575-576.

8. Blanchard A, Guegnard F, Charvet CL, Crisford A, Courtot E, Sauve C, Harmache A, Duguet T, O'Connor V, CastagnoneSereno P, Reaves B, Wolstenholme AJ, Beech RN, HoldenDye L, Neveu C. 2018. Deciphering the molecular determinants of cholinergic anthelmintic sensitivity in nematodes: when novel functional validation approaches highlight major differences between the model Caenorhabditis elegans and parasitic species. PLoS Pathogens, 14(5), e1006996.

9. Blesbois E, Grasseau I, Hermier D. 1999. Changes in lipid content of fowl spermatozoa after liquid storage at 2 to 5 degrees C. Theriogenology, 52(2), 325-334.

10. Borst P, Schinkel AH, Smit JJ, Wagenaar E, Van Deemter L, Smith AJ, Eijdems EW, Baas Zaman GJ. 1993. Classical and novel forms of multidrug resistance and the physiological functions of P-glycoproteins in mammals. Pharmacology and Therapeutics, 60(2), 289-299.

11. Borst P, Zelcer N, van Helvoort A. 2000. ABC transporters in lipid transport. Biochimical and Biophysical Acta, 1486(1), $128-144$.

12. Canitrot Y, Lautier D. 1995. Use of rhodamine 123 for the detection of multidrug resistance. Bulletin du Cancer, 82(9), 687-697. 
13. Castaing M, Loiseau A, Djoudi L. 2003. Effects of cholesterol on dye leakage induced by multidrug-resistance modulators from anionic liposomes. European Journal of Pharmacological Sciences, 18(1), 81-88.

14. Charvet CL, Guegnard F, Courtot E, Cortet J, Neveu C. 2018. Nicotine-sensitive acetylcholine receptors are relevant pharmacological targets for the control of multidrug resistant parasitic nematodes. International Journal of Parasitology - Drugs and Drug Resistance, 8(3), 540-549.

15. Christian AE, Haynes MP, Phillips MC, Rothblat GH. 1997. Use of cyclodextrins for manipulating cellular cholesterol content. Journal of Lipid Researchs, 38(11), 2264-2272.

16. Dey S, Ramachandra M, Pastan I, Gottesman MM, Ambudkar SV. 1998. Photoaffinity labeling of human P-glycoprotein: effect of modulator interaction and ATP hydrolysis on substrate binding. Methods of Enzymology, 292, 318-328.

17. Eytan GD, Regev R, Oren G, Assaraf YG. 1996. The role of passive transbilayer drug movement in multidrug resistance and its modulation. Journal of Biological Chemistry, 271(22), 12897-12902.

18. Feller N, Kuiper CM, Lankelma J, Ruhdal JK, Scheper RJ, Pinedo HM, Broxterman HJ. 1995. Functional detection of MDR1/P170 and MRP/P190-mediated multidrug resistance in tumour cells by flow cytometry. British Journal of Cancer, 72 (3), 543-549.

19. Garnier-Suillerot A, Marbeuf-Gueye C, Salerno M, Loetchutinat C, Fokt I, Krawczyk M, Kowalczyk T, Priebe W. 2001. Analysis of drug transport kinetics in multidrug-resistant cells: implications for drug action. Current Medicinal Chemistry, 8(1), 51-64.

20. Gimpl G, Burger K, Fahrenholz F. 1997. Cholesterol as modulator of receptor function. Biochemistry, 36(36), 10959-10974.

21. Giraud MN, Motta C, Boucher D, Grizard G. 2000. Membrane fluidity predicts the outcome of cryopreservation of human spermatozoa. Human Reproduction, 15(10), 2160-2164.

22. Godoy P, Che H, Beech RN, Prichard RK. 2015. Characterization of Haemonchus contortus P-glycoprotein-16 and its interaction with the macrocyclic lactone anthelmintics. Molecular and Biochemical Parasitology, 204(1), 11-15.

23. Godoy P, Lian J, Beech RN, Prichard RK. 2015. Haemonchus contortus P-glycoprotein-2: in situ localisation and characterisation of macrocyclic lactone transport. International Journal for Parasitology, 45(1), 85-93.

24. Godoy P, Che H, Beech RN, Prichard RK. 2016. Characterisation of P-glycoprotein-9.1 in Haemonchus contortus. Parasites and Vectors, 9, 52.

25. Hoste H, Torres-Acosta JF, Quijada J, Chan-Perez I, Dakheel MM, Kommuru DS, Mueller-Harvey I, Terrill TH. 2016. Interactions between nutrition and infections with Haemonchus contortus and related gastrointestinal nematodes in small ruminants. Advances in Parasitology, 93, 239-351.

26. Ilangumaran S, Hoessli DC. 1998. Effects of cholesterol depletion by cyclodextrin on the sphingolipid microdomains of the plasma membrane. Biochemical Journal, 335(Pt 2), 433440.

27. Issouf M, Guegnard F, Koch C, Le Vern Y, Blanchard-Letort A, Che H, Beech RN, Kerboeuf D, Neveu C. 2014. Haemonchus contortus P-glycoproteins interact with host eosinophil granules: a novel insight into the role of $\mathrm{ABC}$ transporters in hostparasite interaction. PLoS One, 9(2), e87802.

28. Kaschny M, Demeler J, Janssen IJ, Kuzmina TA, Besognet B, Kanellos T, Kerboeuf D, von Samson-Himmelstjerna G, Krucken J. 2015. Macrocyclic lactones differ in interaction with recombinant P-glycoprotein 9 of the parasitic nematode Cylicocylus elongatus and ketoconazole in a yeast growth assay. PLoS Pathogens, 11(4), e1004781.
29. Kerboeuf D, Aycardi J. 1999. Unexpected increased thiabendazole tolerance in Haemonchus contortus resistant to anthelmintics by modulation of glutathione activity. Parasitology Research, 85(8-9), 713-718.

30. Kerboeuf D, Aycardi J, Soubieux D. 1996. Flow-cytometry analysis of sheep-nematode egg populations. Parasitology Research, 82(4), 358-363.

31. Kerboeuf D, Chambrier P, Le Vern Y, Aycardi J. 1999. Flow cytometry analysis of drug transport mechanisms in Haemonchus contortus susceptible or resistant to anthelmintics. Parasitology Research, 85(2), 118-123.

32. Kerboeuf D, Guegnard F, Le Vern Y. 2002. Analysis and partial reversal of multidrug resistance to anthelmintics due to P-glycoprotein in Haemonchus contortus eggs using Lens culinaris lectin. Parasitology Research, 88(9), 816-821.

33. Kerboeuf D, Blackhall W, Kaminsky R, von SamsonHimmelstjerna G. 2003. P-glycoprotein in helminths: function and perspectives for anthelmintic treatment and reversal of resistance. International Journal of Antimicrobial Agents, 22(3), 332-346.

34. Kerboeuf D, Guegnard F, Vern YL. 2003. Detection of P-glycoprotein-mediated multidrug resistance against anthelmintics in Haemonchus contortus using anti-human mdrl monoclonal antibodies. Parasitology Research, 91(1), 79-85.

35. Kerboeuf D, Riou M, Neveu C, Issouf M. 2010. Membrane drug transport in helminths. Anti-Infective Agent in Medicinal Chemistry, 9, 113-129.

36. Kim RB. 2002. Transporters and xenobiotic disposition. Toxicology, 181-182, 291-297.

37. Kimura Y, Kioka N, Kato H, Matsuo M, Ueda K. 2007. Modulation of drug-stimulated ATPase activity of human MDR1/P-glycoprotein by cholesterol. Biochemical Journal, 401(2), 597-605.

38. Klein U, Gimpl G, Fahrenholz F. 1995. Alteration of the myometrial plasma membrane cholesterol content with betacyclodextrin modulates the binding affinity of the oxytocin receptor. Biochemistry, 34(42), 13784-13793.

39. Klein C, Pillot T, Chambaz J, Drouet B. 2003. Determination of plasma membrane fluidity with a fluorescent analogue of sphingomyelin by FRAP measurement using a standard confocal microscope. Brain Research Protocols, 11(1), 46-51.

40. Kohler P. 2001. The biochemical basis of anthelmintic action and resistance. International Journal of Parasitology, 31(4), 336-345.

41. Kwa MS, Kooyman FN, Boersema JH, Roos MH. 1993. Effect of selection for benzimidazole resistance in Haemonchus contortus on beta-tubulin isotype 1 and isotype 2 genes. Biochemical and Biophysical Research Communications, 191(2), 413-419.

42. Kwa MS, Veenstra JG, Roos MH. 1994. Benzimidazole resistance in Haemonchus contortus is correlated with a conserved mutation at amino acid 200 in beta-tubulin isotype 1 . Molecular and Biochemical Parasitology, 63(2), 299-303.

43. Laberge RM, Ambadipudi R, Georges E. 2014. P-glycoprotein mediates the collateral sensitivity of multidrug resistant cells to steroid hormones. Biochemical and Biophysical Research Communications, 447(4), 574-579.

44. Le Jambre LF, Dobson RJ, Lenane IJ, Barnes EH. 1999. Selection for anthelmintic resistance by macrocyclic lactones in Haemonchus contortus. International Journal of Parasitology, 29(7), 1101-1111.

45. Lee EY, Jeong PY, Kim SY, Shim YH, Chitwood DJ, Paik YK. 2009. Effects of sterols on the development and aging of Caenorhabditis elegans. Methods in Molecular Biology, 462, 167-179. 
46. Lespine A. 2013. Lipid-like properties and pharmacology of the anthelmintic macrocyclic lactones. Expert Opinion on Drug Metabolism and Toxicology, 9(12), 1581-1595.

47. Lespine A, Menez C, Bourguinat C, Prichard RK. 2012. P-glycoproteins and other multidrug resistance transporters in the pharmacology of anthelmintics: prospects for reversing transport-dependent anthelmintic resistance. International Journal of Parasitology - Drugs and Drug Resistances, 2, 58-75.

48. Lu P, Liu R, Sharom FJ. 2001. Drug transport by reconstituted P-glycoprotein in proteoliposomes. Effect of substrates and modulators, and dependence on bilayer phase state. European Journal of Biochemistry, 268(6), 1687-1697.

49. Luker GD, Pica CM, Kumar AS, Covey DF, Piwnica-Worms D. 2000. Effects of cholesterol and enantiomeric cholesterol on P-glycoprotein localization and function in low-density membrane domains. Biochemistry, 39(26), 7651-7661.

50. Marechal E, Riou M, Kerboeuf D, Beugnet F, Chaminade P, Loiseau PM. 2011. Membrane lipidomics for the discovery of new antiparasitic drug targets. Trends in Parasitology, 27(11), 496-504.

51. Marques HMC. 2010. A review on cyclodextrin encapsulation of essential oils and volatiles. Flavour and Fragrance Journal., 25(5), 313-326.

52. Menez C, Mselli-Lakhal L, Foucaud-Vignault M, Balaguer P, Alvinerie M, Lespine A. 2012. Ivermectin induces P-glycoprotein expression and function through mRNA stabilization in murine hepatocyte cell line. Biochemical Pharmacology, 83(2), 269-278.

53. Menez C, Alberich M, Courtot E, Guegnard F, Blanchard A, Aguilaniu H, Lespine A. 2019. The transcription factor NHR-8: a new target to increase ivermectin efficacy in nematodes. PLoS Pathogens, 15(2), e1007598.

54. Mora MP, Tourne-Peteilh C, Charveron M, Fabre B, Milon A, Muller I. 1999. Optimisation of plant sterols incorporation in human keratinocyte plasma membrane and modulation of membrane fluidity. Chemistry Physics Lipids, 101(2), 255-265.

55. Mukhopadhyay K, Kohli A, Prasad R. 2002. Drug susceptibilities of yeast cells are affected by membrane lipid composition. Antimicrobial Agents Chemotherapy, 46(12), 3695-3705.

56. Oldfield E, Chapman D. 1972. Dynamics of lipids in membranes: heterogeneity and the role of cholesterol. FEBS Letters, 23(3), 285-297.

57. Page AP, Stepek G, Winter AD, Pertab D. 2014. Enzymology of the nematode cuticle: a potential drug target? International Journal of Parasitology - Drugs and Drug Resistances, 4(2), 133-141.

58. Pallares-Trujillo J, Lopez-Soriano FJ, Argiles JM. 2000. Lipids: a key role in multidrug resistance? (Review). International Journal of Oncology, 16(4), 783-798.

59. Peelman F, Labeur C, Vanloo B, Roosbeek S, Devaud C, Duverger N, Denefle P, Rosier M, Vandekerckhove J, Rosseneu M. 2003. Characterization of the ABCA transporter subfamily: identification of prokaryotic and eukaryotic members, phylogeny and topology. Journal of Molecular Biology, 325(2), 259-274.

60. Prichard RK, Hall CA, Kelly JD, Martin IC, Donald AD. 1980. The problem of anthelmintic resistance in nematodes. Australian Veterinary Journal, 56(5), 239-251.

61. Qu Q, Sharom FJ. 2002. Proximity of bound Hoechst 33342 to the ATPase catalytic sites places the drug binding site of P-glycoprotein within the cytoplasmic membrane leaflet. Biochemistry, 41(14), 4744-4752.

62. Qu Q, Chu JW, Sharom FJ. 2003. Transition state P-glycoprotein binds drugs and modulators with unchanged affinity, suggesting a concerted transport mechanism. Biochemistry, 42(5), 1345-1353.
63. Qu Q, Russell PL, Sharom FJ. 2003. Stoichiometry and affinity of nucleotide binding to P-glycoprotein during the catalytic cycle. Biochemistry, 42(4), 1170-1177.

64. Ramos F, Portella LP, Rodrigues Fde S, Reginato CZ, Potter L, Cezar AS, Sangioni LA, Vogel FS. 2016. Anthelmintic resistance in gastrointestinal nematodes of beef cattle in the state of Rio Grande do Sul, Brazil. International Journal of Parasitology - Drugs and Drug Resistances, 6(1), 93-101.

65. Riou M. 2008. "From eggs per gram to genes"-21st International Conference of the World Association for the Advancement of Veterinary Parasitology (WAAVP 2007). Parasite, 15(2), 183-184.

66. Riou M, Guegnard F, Le Vern Y, Kerboeuf D. 2003. Modulation of the multidrug resistance (MDR) system in the nematode Haemonchus contortus by changing cholesterol content: effects on resistance to anthelmintics. Journal of Antimicrobial Chemotherapy, 52(2), 180-187.

67. Riou M, Koch C, Kerboeuf D. 2005. Increased resistance to anthelmintics of Haemonchus contortus eggs associated with changes in membrane fluidity of eggshells during embryonation. Parasitology Reseach, 95(4), 266-272.

68. Riou M, Grasseau I, Blesbois E, Kerboeuf D. 2007. Relationships between sterol/phospholipid composition and xenobiotic transport in nematodes. Parasitology Research, 100(5), 1125-1134.

69. Riou M, Guegnard F, Sizaret PY, Le Vern Y, Kerboeuf D. 2010. Drug resistance is affected by colocalization of P-glycoproteins in raft-like structures unexpected in eggshells of the nematode Haemonchus contortus. Biochemical Cell and Biology, 88(3), 459-467.

70. Rothnie A, Theron D, Soceneantu L, Martin C, Traikia M, Berridge G, Higgins CF, Devaux PF, Callaghan R. 2001. The importance of cholesterol in maintenance of P-glycoprotein activity and its membrane perturbing influence. European Biophysical Journal, 30(6), 430-442.

71. Schinkel AH. 1997. The physiological function of drugtransporting P-glycoproteins. Seminars in Cancer Biology, 8(3), 161-170.

72. Schinkel AH, Mol CA, Wagenaar E, van Deemter L, Smit JJ, Borst P. 1995. Multidrug resistance and the role of P-glycoprotein knockout mice. European Journal of Cancer, 31A(7-8), 1295-1298.

73. Shechter E, Rossignol B. 1997. Biochimie et biophysique des membranes. Aspects structuraux et fonctionnels. Paris (France): Dunod, 459 p.

74. Shinitzky M, Barenholz Y. 1974. Dynamics of the hydrocarbon layer in liposomes of lecithin and sphingomyelin containing dicetylphosphate. Journal of Biological Chemistry, 249(8), 2652-2657.

75. Shinitzky M, Barenholz Y. 1978. Fluidity parameters of lipid regions determined by fluorescence polarization. Biochimical and Biophysical Acta, 515(4), 367-394.

76. Sinicrope FA, Dudeja PK, Bissonnette BM, Safa AR, Brasitus TA. 1992. Modulation of P-glycoprotein-mediated drug transport by alterations in lipid fluidity of rat liver canalicular membrane vesicles. Journal of Biological Chemistry, 267(35), 24995-25002.

77. Smit JJ, Schinkel AH, Oude Elferink RPJ, Groen AK, Wagenaar E, van Deemter L, Mol CAAM, Ottenhoff R, van der Lugt NMT, van Roon MA, van der Valk MA, Offerhaus JA, Berns AJM, Borst P. 1993. Homozygous disruption of the murine mdr2 Pglycoprotein gene leads to a complete absence of phospholipid from bile and to liver disease. Cell, 75(3), 451-462.

78. Smit JJ, Schinkel AH, Mol CA, Majoor D, Mooi WJ, Jongsma AP, Lincke CR, Borst P. 1994. Tissue distribution of the human MDR3 P-glycoprotein. Laboratory Investigation, 71(5), 638-649. 
79. Varadyova Z, Pisarčíková J, Babják M, Hodges A, Mravčáková D, Kišidayová S, Königová A, Vadlejch J, Várady M. 2018. Ovicidal and larvicidal activity of extracts from medicinal-plants against Haemonchus contortus. Experimental Parasitology, 195, 71-77.

80. Waller PJ. 1999. International approaches to the concept of integrated control of nematode parasites of livestock. International Journal of Parasitology, 29(1), 155-164; discussion 183-184.

81. Yoshimoto H, Takeo T, Irie T, Nakagata N. 2017. Fertility of cold-stored mouse sperm is recovered by promoting acrosome reaction and hyperactivation after cholesterol efflux by methylbeta-cyclodextrin. Biology and Reproduction, 96(2), 446-455.

82. Yunomae K, Arima H, Hirayama F, Uekama K. 2003. Involvement of cholesterol in the inhibitory effect of dimethyl-beta-cyclodextrin on P-glycoprotein and MRP2 function in Caco-2 cells. FEBS Letters, 536(1-3), 225-231.

83. Zimniak P, Pikula S, Bandorowicz-Pikula J, Awasthi YC. 1999. Mechanisms for xenobiotic transport in biological membranes. Toxicology Letters, 106(2-3), 107-118.

Cite this article as: Riou M, Guégnard F, Le Vern Y, Grasseau I, Koch C, Blesbois E \& Kerboeuf D. 2020. Effects of cholesterol content on activity of P-glycoproteins and membrane physical state, and consequences for anthelmintic resistance in the nematode Haemonchus contortus. Parasite 27, 3.

\section{$\bigoplus$ PARASTE}

An international open-access, peer-reviewed, online journal publishing high quality papers on all aspects of human and animal parasitology

Reviews, articles and short notes may be submitted. Fields include, but are not limited to: general, medical and veterinary parasitology; morphology, including ultrastructure; parasite systematics, including entomology, acarology, helminthology and protistology, and molecular analyses; molecular biology and biochemistry; immunology of parasitic diseases; host-parasite relationships; ecology and life history of parasites; epidemiology; therapeutics; new diagnostic tools.

All papers in Parasite are published in English. Manuscripts should have a broad interest and must not have been published or submitted elsewhere. No limit is imposed on the length of manuscripts.

Parasite (open-access) continues Parasite (print and online editions, 1994-2012) and Annales de Parasitologie Humaine et Comparée (1923-1993) and is the official journal of the Société Française de Parasitologie. 